\title{
Cost-effectiveness of the Family Planning Programme in Pakistan*
}

\author{
KHALEDA MANZOOR
}

\section{THEORETICAL FRAMEWORK}

Family Planning in the context of developing countries particularly Pakistan can be classified as "public good" or "merit good". It is because that although family planning services are consumed by private individuals it is accompanied by significant external benefits/costs. This constitutes the reason on efficiency ground for public provision of family planning services. There are equity grounds as well for public provision of these services. The public provision of family planning services is based on paternalistic argument that individual ought to consume them but are not acting in their own self-interest and are not ready to purchase them without substantial subsidisation. It may be one of the reasons for public provision of family planning, but, on normative grounds it is hard to justify the provision of merit good and still maintain the two basic premises of classical welfare economics: that individuals are rational and that individuals know their own interest best. In the context, of developing countries these arguments however, take a different dimension. First, in the absence of a democratic welfare state with high rate of unemployment, lack of unemployment insurance and social security, lack of old age security and pension a pertinent question to ask is: are individuals particularly from middle and lower income groups acting irrationally by demanding more children if children are perceived as a source of social and economic support in old age as well as being a source of additional family income.

Second, in the socio-economic structure of Pakistan which is predominantly agrarian, feudal, patriarchal and patrilineal son preference is a predominant reason to demand more children. received.

* Owing to unavoidable circumstances, the discussant's comments on this paper have not been Islamabad.

Khaleda Manzoor is Senior Research Fellow in National Institute of Population Studies,

Author's Note: I acknowledge the technical support provided by Mr Geoffrey Hoare, Faculty Member, Centre for Health Management and Planning, University of Keele, Germany. Any remaining errors and ommissions are my sole responsibility. 
Third, high rate of illiteracy, lower socio-economic and dependency status of women, lack of awareness of family planning and need to limit family size and fatalistic and religious attitudes are important sociological factors determining attitudes towards high fertility.

The question to address is: what is the most cost-effective way of providing family planning service from a whole range of service delivery modes and methods.

\section{COST-EFFECTIVENESS ANALYSIS}

The primary concern of cost-effectiveness analysis is to estimate the demographic impact of family planning and the costs of family planning. Cost-effectiveness can be measured by dividing programme inputs by outputs to derive a per unit cost. There are numerous possible comparisons of inputs to outputs but the one most frequently used by family planning programmes is total programme costs per couple year of protection. Cost-effectiveness can be increased by reducing the unit cost of protection. The question for the Population Welfare Programme to address is how to maximise the protection offered and modify inputs to reduce per unit costs.

\section{Review of Earlier Cost-effectiveness Studies}

"Estimates of the costs of providing family planning services have been used to assert that some types of programmes are more efficient than others. However, variations in costs may exist because of differences in the mixes of services or in the demand for services and the availability of alternative services. Moreover, cost estimates may vary simply because researchers used different methodologies, treated programme output in widely varying ways or did not always take differences in programme settings into account. The authors recommended that a common methodology be developed for determining the costs of family planning so that better comparisons can be made, programme characteristics can be fully understood before comparisons are attempted and programmes from clearly different settings are not directly compared" [Janowitz and Bratt (1992)].

The Amsterdam Declaration, adopted at the 1989 International Forum on Population in the Twenty-first Century, states that:

"Perhaps the simplest technique for forecasting financial requirements for family planning services is to calculate future costs in terms of the average annual current cost per contraceptive user and projected number of users by the year 2000" [UNFPA (1989)]. Most experts believe that the per capita cost varies widely 
across countries and the best estimates range between $\$ 10$ and $\$ 20$. Other methods of indirectly estimating the per capita user cost also confirm the wide variation in that figure. For example, a simple analysis of dividing annual expenditures for family planning by the number of users for the same year in a group of 27 developing countries indicates that, in a majority of cases, the per capita cost varies between $\$ 8$ and \$ 11 [AID (1989)]. A study undertaken by the World Bank [Bulatao (1985)] estimates the per capita cost to range between $\$ 10$ and $\$ 15$. Also a simple ratio of estimated annual cost expenditures for family planning in all developing countries in 1987 ( $\$ 3$ billion) and total number of projected users (326 million) also yields a per capita user cost of around $\$ 10$. All these estimates are affected by a host of factors, including mode of service delivery, national per capita income, exchange rates, duration of programme effort, programme efficiency, and attribution of direct costs to family planning services. On the other hand, a recent study has attempted to estimate the per capita cost of users by desegregating the cost of the commodities required and the cost of service delivery for the total number of users in the year 2000 . The average cost per user in the year 2000 by this method is estimated at \$15 [in real terms] [Gillespie (1989)].

\section{Cost and Output Indicators}

The Total Programme Costs in our model comprises of the following components:

- Staffing Costs;

- capital Costs;

- operating Costs;

- cost of Contraceptives; and

- indirect Overheads (Federal, Provincial and District Administrative Costs).

The output indicators are as follows:

- Couple Year of Protection (CYP) which is a standard measure universally accepted;

- No. of Births Averted; and

- actual Supply.

In the context of Pakistan, the relationship between birth averted and CYP is as: 
- 1 Birth Averted is equivalent to 3.75 Couple Years Protection; 1 CYP is equivalent to 0.27 Births Averted per annum

\section{OBJECTIVES OF THE PRESENT STUDY}

The specific objectives of the present study are as follows:

1. Compare the per unit costs of different type of service outlets;

2. compare the per unit costs of different contraceptive methods; and

3. highlight the methodological issues related to costing studies.

\section{LIMITATIONS OF THE STUDY}

The present study has the following limitations due to which the findings of the study should be interpreted carefully and should not be generalised:

- The data used in the study is for one district of Punjab. It provides a partial picture of the whole scenario. Different results might occur for other districts of Punjab and other provinces.

- Only one-year data (1991-92) have been used as a sample; thus, the data provide a snapshot of family planning cost-effectiveness at one point in time.

- Couple year of protection and birth averted are the only measures of output used in the study as they enjoy some universality among family planning programme despite their imperfections.

- The completeness or accuracy of all data used cannot be totally verified.

- The paper does not attempt to make judgement about the quality of the programme.

This paper however, provides a methodology and sets the stage for further inquiries into the issue.

\section{RELATIONSHIP BETWEEN OUTPUT INDICATORS}

According to Table 1832.29 units of condom will avert one birth in 3.75 CYP if adjusted by .0045 (less than one percent effective). In other words 832.29 units of condom will avert .27 birth in one year. By the same arguments 5.76 IUD cases will avert one birth in 3.75 CYP if it is adjusted by .65 (65 percent effective) and since one IUD case offers $3.5 \mathrm{CYP}$ it will avert .94 births or approximately one birth per year. If IUDs are considered to be 100 percent effective it will avert 1.65 births in 3.5 CYP. 
Table 1

Relationship of Number of Units of Contraceptive Method, Birth Averted and CYP (Seventh Five-Year Plan Figures)

\begin{tabular}{|c|c|c|c|c|c|c|c|}
\hline Method & $\begin{array}{l}\text { Number } \\
\text { Units } \\
\text { Required } \\
\text { to Avert } \\
\text { One Birth } \\
\end{array}$ & $\begin{array}{c}\text { Adjust- } \\
\text { ment } \\
\text { Coeff- } \\
\text { icient } \\
\text { for CYP }\end{array}$ & $\begin{array}{l}\text { Equiva- } \\
\text { lent } \\
\text { Couple } \\
\text { Years } \\
\text { Protec- } \\
\text { tion } \\
(\mathrm{CYP}) \\
(\mathrm{C} 2 \times \mathrm{C} 3)\end{array}$ & $\begin{array}{c}\text { Birth } \\
\text { Averted } \\
\text { Equiva- } \\
\text { lent } \\
\text { per Year }\end{array}$ & $\begin{array}{c}\text { BA per } \\
\text { CYP } \\
\text { (C5/C4) }\end{array}$ & $\begin{array}{l}\text { CYPs } \\
\text { Dura- } \\
\text { tion }\end{array}$ & $\begin{array}{l}\text { Equiva- } \\
\text { lent } \\
\text { Births } \\
\text { Averted } \\
\text { per } \\
\text { Method } \\
\text { (C6×C7) }\end{array}$ \\
\hline Condom & 832.29 & 0.0045 & 3.75 & 1 & 0.27 & 1 & 0.27 \\
\hline Oral & 97.38 & 0.0385 & 3.75 & 1 & 0.27 & 1 & 0.27 \\
\hline IUD & 5.76 & 0.6500 & 3.75 & 1 & 0.27 & 3.5 & 0.94 \\
\hline INJ. & 41.61 & 0.0900 & 3.75 & 1 & 0.27 & 1 & 0.27 \\
\hline CS & 3.74 & 1.0000 & 3.75 & 1 & 0.27 & 10 & 2.67 \\
\hline Foam & 33.3 & 0.1125 & 3.75 & 1 & 0.27 & 1 & 0.27 \\
\hline
\end{tabular}

Source : Monitoring and Statistics Wing, Ministry of Population Welfare and Johnson (1991), USAID Task Force Report.

Recent changes made for the Eighth Five-Year Plan indicate new coefficients for various methods as more appropriate which are reported in Table 2.

Table 2

Relationship of Number of Units of Contraceptive Method, Birth Averted and CYP (Eighth Five-Year Plan Figures)

\begin{tabular}{|c|c|c|c|c|c|c|c|}
\hline Method & $\begin{array}{l}\text { Number } \\
\text { Units } \\
\text { Required } \\
\text { to Avert } \\
\text { One Birth }\end{array}$ & $\begin{array}{c}\text { Adjust- } \\
\text { ment } \\
\text { Coeff- } \\
\text { icient } \\
\text { for CYP }\end{array}$ & $\begin{array}{l}\text { Equiva- } \\
\text { lent } \\
\text { Couple } \\
\text { Years } \\
\text { Protec- } \\
\text { tion } \\
(\mathrm{CYP}) \\
(\mathrm{C} 2 \times \mathrm{C} 3) \\
\end{array}$ & $\begin{array}{c}\text { Birth } \\
\text { Averted } \\
\text { Equiva- } \\
\text { lent } \\
\text { perYear }\end{array}$ & $\begin{array}{c}\text { BA per } \\
\text { CYP } \\
(\mathrm{C} 5 / \mathrm{C} 4) \\
\end{array}$ & $\begin{array}{c}\text { CYPs } \\
\text { Dura- } \\
\text { tion }\end{array}$ & $\begin{array}{c}\text { Equiva- } \\
\text { lent } \\
\text { Births } \\
\text { Averted } \\
\text { per } \\
\text { Method } \\
\text { (C6 } 6 \times \mathrm{C}) \\
\end{array}$ \\
\hline Condom & 936.329 & 0.0040 & 3.75 & 1 & 0.27 & 1 & 0.27 \\
\hline Oral & 80.259 & 0.0467 & 3.75 & 1 & 0.27 & 1 & 0.27 \\
\hline IUD & 5.352 & 0.6998 & 3.75 & 1 & 0.27 & 3.5 & 0.94 \\
\hline INJ. & 40.574 & 0.0923 & 3.75 & 1 & 0.27 & 1 & 0.27 \\
\hline CS & 3.745 & 1.0000 & 3.75 & 1 & 0.27 & 10 & 2.67 \\
\hline Foam & 41.615 & 0.0900 & 3.75 & 1 & 0.27 & 1 & 0.27 \\
\hline
\end{tabular}

Source: Monitoring and Statistics Wing, Ministry of Population Welfare and Johnson (1991), USAID Task Force Report. 
Clearly, the effectiveness of IUDs and contraceptive methods is not limited solely to the year in which they are delivered. This is not a problem in itself, indeed, it is one of the strengths of such methods that they yield a stream of benefits over several years. Where difficulties do arise is in ensuring that one is consistent in how one compares costs and outcomes across different methods.

In the case of most contraceptive methods, most costs and all benefits are limited to a single year. On the cost side there are some resources, such as capital equipment and buildings, where the costs may be incurred in a single year, and yet, where they are consumed (i.e. yield benefits) over several years. Economists have developed special techniques to deal with such anomalies arising from the differential timing of costs and benefits. The technique of discounting is used to translate 'one-off' or periodic costs into an annual equivalent cost which more accurately reflects their partial consumption in each year of their life. Once this adjustment is made it is usually possible to express and compare the costs incurred in a single year with the benefits realised in that same year.

In the case of IUDs and contraceptive surgery one must recognise that a 'stream' of benefits that are produced and relate programme costs to the total benefit rather than to the benefits produced in a single year. The latter approach correctly expresses the programmes total costs in relation to the total benefits derived. In other words, all benefits are compared to all costs.

Whilst economic evaluation does have its strengths, it also suffers from several weaknesses. One particular problem relates to the difficulty in identifying a single measure of programme outcome that captures all the relevant dimensions of a programme's output.

Measures of CYP and BA focus primarily on supply volume and assumed impact. As such, they give little information on the ways in which services are provided, nor their acceptability to the client. Two methods of family planning which score similarly in terms of cost per CYP, may differ markedly in terms of their acceptability to, or popularity with a client. Likewise, the measure of Births Averted provides little information as to the popularity with a client.

\section{ASSUMPTIONS OF THE STUDY}

The present study is based on the following assumptions:

1. Sixty percent of Total Programme Cost was apportioned to FP. Based on the Functional Task Analysis Study the Total Cost of FP was appor- 
tioned to different methods according to the following Scheme:

\begin{tabular}{lc}
\hline Contraceptive Method & Apportionment Weight \\
\hline IUD & $30 \%$ \\
Condom & $10 \%$ \\
Injectable & $20 \%$ \\
Pill & $10 \%$ \\
Cont. Surgery & $30 \%$ \\
Total & 100 \\
\hline
\end{tabular}

2. The Federal Headquarter costs were equally apportioned to the four provinces. The Provincial Headquarter costs were equally apportioned to all the districts within the province. Ninety percent of the District Headquarter costs were apportioned to the FWCs; 5 percent to MSUs and 5 percent to RHSs. This was done on the basis of the total size and volume of activity of each type of service outlet.

3. The cost apportionment for both the Reproductive Health Services were done on the following basis:

Apportionment to

Costs

Contraceptive Surgery

Staffing Costs (of those Involved in CS)

$25 \%$

Capital Costs (Building and Operation

Theater Equipments)

Operational Costs

$25 \%$

$2 \%$

4. To adjust for overreporting the output figures for condoms and pills were discounted by 60 percent and 50 percent respectively based on the field observations.

5. Of the total contraceptive surgery output, 50 percent was apportioned to FWCs and remaining 50 percent was apportioned to RHSs and MSUs by a ratio of 75 percent and 25 percent respectively. The apportionment to each outlet within each type was done on the basis of the volume of activity of each outlet.

\section{SAMPLE-A DISTRICT}

The study was conducted in Sheikhupura district-a representative district 
of the Punjab. It had locational advantage being close to the Provincial Headquarters in Lahore. It was also considered a model district as it has all types of services available. There were 35 Family Welfare Centres, 2 Reproductive Services Centres (B type) and 2 Mobile Service Units operating in the district in 1991-92, the period of study. The MSUs were not operating during the field work due to lack of staff because of the ban on employment. The district has a population of about 6-7 lacs and there is growing consciousness about family planning. The district is divided into four administrative units called tehsils.

\section{Cost-effectiveness of Family Welfare Centres (FWCs)}

All FWCs have a more or less similar cost structure with slight variations due primarily to cost of contraceptives. Staffing, capital and operating costs made up for 49 percent to 53 percent of the total programme cost; contraceptive costs formed 23 percent to 26 percent whereas indirect overheads formed 24 percent to 25 percent of the total programme costs (see Table 3 ).

Table 3

Cost-effectiveness Measures of FWCs

(District Level)

\begin{tabular}{lrrrrrr}
\hline & FP & CONDOM & INJ & PILL & IUD & SURG. \\
\hline $\begin{array}{l}\text { Total Cost/Birth } \\
\begin{array}{l}\text { Averted } \\
\text { Total Cost/Birth }\end{array}\end{array}$ & 316 & 1458 & 3901 & 3296 & 107 & 676 \\
$\begin{array}{l}\text { Averted (Adj) } \\
\text { Total Cost/Unit }\end{array}$ & 325 & 2431 & 3901 & 5964 & 107 & 676 \\
Total Cost/Unit (Adj)* & - & 2 & 94 & 33 & 109 & 1805 \\
Total Cost/CYP & 124 & 390 & 1046 & 863 & 47 & 181 \\
Total Cost/CYP (Adj)* & 129 & 650 & 1046 & 1702 & 47 & 181 \\
\hline "60 percent of condom and 50 percent of pill reported figures considered. & & & & & & \\
\end{tabular}

At the district level, the average cost of one birth averted is Rs 316. When adjusted for over-reporting the average cost of one birth averted is Rs 325. IUD has the least cost whereas injectables has the highest cost and if adjusted then pill has the highest cost per birth averted. The cost of surgery is almost six times higher than the cost of an IUD. 


\section{Cost-effectiveness of Mobile Service Units (MSUs)}

Twelve and a half percent of the total surgery cases were apportioned to the two MSUs by the number of cases reported by each. The cost-effectiveness measures of MSUs by various methods are given in Table 4.

\section{Table 4}

Cost-effectiveness Measures of MSUs by Methods

(Tehsil and District Level)

(In Rs)

\begin{tabular}{lrrrrrr}
\hline & FP & CONDOM & INJ. & PILL & IUD & SURG. \\
\hline Nankana Tehsil & & & & & & \\
Cost/Birth Averted & 346 & - & 29416 & 148 & 458 & \\
Cost/Unit & - & - & 774 & - & 156 & 1223 \\
Cost/CYP & 137 & - & 8404 & - & 68 & 122 \\
Sheikhupura Tehsil & & & & & & \\
Cost/Birth Averted & 271 & - & 58479 & 145 & 218 & \\
Cost/Unit & - & 2847 & 943 & 2591 & 153 & 582 \\
Cost/Unit(Adj)* & - & 4746 & 943 & 4751 & 153 & 582 \\
Cost/CYP & 97 & - & 9747 & - & 67 & 58 \\
District Level & & & & & & \\
Cost/Birth Averted & 309 & - & 43948 & 147 & 338 & \\
Cost/Unit & - & 1424 & 859 & 1296 & 155 & 903 \\
Cost/Unit(Adj)* & - & 2373 & 859 & 2376 & 155 & 903 \\
Cost/CYP & 117 & - & 9076 & - & 68 & 90 \\
\hline "60 percent of condom and & & & & & & \\
\hline
\end{tabular}

60 percent of condom and 50 percent of pill reported figures considered.

The average cost per birth averted ranges between Rs 271 and Rs 346 with district average of Rs 309 .

IUD is the least cost method for each birth averted for both MSUs. Injectable has the highest cost in both cases due to extremely low volume of its output. The cost of surgery per birth averted ranges between Rs 218 and Rs 458 with Rs 338 as district average.

\section{COMPARISON OF FWCs AND MSUS}

Comparison of the district cost per birth averted of FWCs and MSUs indicate that per unit cost of IUD is cheaper in FWCs whereas per unit cost of surgery is cheaper in MSUs. 
Nature of Service Delivery of IUD and Surgery (FWCs, MSUs and RHS)

\begin{tabular}{|c|c|c|c|c|}
\hline \multicolumn{2}{|c|}{ FWCs } & \multicolumn{2}{|c|}{ MSUs } & RHS \\
\hline IUD & Surgery & IUD & Surgery & Surgery \\
\hline $\begin{array}{l}\text { Motivation } \\
\text { Insertion }\end{array}$ & $\begin{array}{l}\text { Motivation } \\
\text { Transportation }\end{array}$ & Motivation & Motivation & $\begin{array}{l}\text { Conducting } \\
\text { Operation }\end{array}$ \\
\hline
\end{tabular}

Comparing the district costs of MSUs and FWCs, all methods involve higher cost per birth averted by the MSUs than the FWCs except for IUD. Condoms and injectable have much higher cost in case of MSUs due to extremely low volume of output. Surgery costs six times higher than IUDs by MSUs whereas it costs seventeen times higher than IUDs for each unit in case of FWCs. IUDs have higher cost in case of MSUs than FWCs. The major factors behind the higher cost of MSUs are higher transportation costs and low volume of outputs.

Mobile Service Units (MSUs) are the only source of outreach services. In order to minimise the costs of MSUs any or a combination of the following measures may be adopted:

- To try and increase the number of clients per outreach visits;

- to try and realise savings in transport costs for MSUs; and

- to use MSUs to provide those methods of contraception where they have a relative, even if not an absolute cost advantage for e.g. surgery and IUD.

While comparing the cost of MSUs and FWCs, the following points should be considered:

1. The cost to the user also needs to be taken into account when reviewing these figures. If it is far more expensive for a client (in terms of time and travel) to attend a static clinic. Investment in MSUs lowers the client's cost. Any analysis of placement of service sites should consider whether in fact clients are being saved some expense, and how much.

2. It may be possible to do the following: (i) estimate the average distance of a community to a static clinic and average waiting time; (ii) calculate total client time; (iii) multiply client time by a standard or minimum wage in the area; and (iv) compare client cost against the difference in expense between outreach and static services. In the present situation however, the lack of adequate basic health and family planning facilities and lack 
of accessibility particularly in the rural areas necessitate the investment in and operation of MSUs.

3. The cost calculation in the present study takes into account the monetary costs to service provider only and not the direct and indirect costs to service users (e.g. time, travel and distance costs) that result in the aggregate social and private costs of FWCs and MSUs to be closer. The inclusion of social costs by adding the estimated monetary value of travel time and travel costs of clients to FWCs will increase the aggregate cost of FWCs and the relative costs of FWCs and MSUs will be different vis $\grave{a}$ vis the present cost comparison.

4. In case of MSUs the travel time and travel costs of clients are saved and borne by the service providers which makes it appear more costly uis $d$ vis the cost of FWCs whereas these costs are borne by the service users in case of FWCs. But given the realistic situation that most of the users of FWCs at least for temporary methods are women/couples living in the vicinity of the FWCs the social costs in terms of travel time and travel costs may not be significant. This observation however, cannot be generalised.

\section{COST-EFFECTIVENESS OF REPRODUCTIVE HEALTH SERVICES (RHS)}

The RHS centres receive an Institutional Reimbursement Cost (IRC) of Rs 235 per case for B type centres which only covers partial payment to staff, cost of medicines and payment for transportation of clients.

Thirty seven and a half percent of total surgery cases were apportioned to RHS centres. Of the total cases apportioned to RHS centres, 6 percent was apportioned to Nankana RHS whereas 94 percent was apportioned to Sheikhupura RHS in proportion to their actual performance.

Table 5 indicates a significant variation in the per unit costs of surgical contraception between the two RHS centres. Sheikhupura RHS provides surgical contraception at lower cost.

\section{INTERPRETATION OF PER UNIT COSTS OF SURGERY - JOINT COSTS AND OUTPUT}

The district cost of surgery for a birth averted can be divided into two components: (i) Cost of motivation and transportation which are incurred by FWCs and MSUs and (ii) Actual cost of contraceptive surgery delivery incurred by RHS 
Table 5

Cost-effectiveness Measures of RHS Centres

(Tehsil and District Level)

(In Rs)

Surgical Contraception

Sheikhupura RHS

Total Cost/Birth Averted

485

Total Cost/Surgery

1297

Total Cost/CYP

130

Nankana RHS

Total Cost/Birth Averted

3396

Total Cost/Surgery

9080

Total Cost/CYP

908

District Level

Total Cost/Birth Averted

Total Cost/Surgery

Total Cost/CYP

centres. The total district costs of surgery amounts to Rs 676 (FWCs)/Rs 338 (MSUs) and Rs 1941 (RHS). In other words, the actual cost of surgery per birth averted amounts to Rs 2617 if clients are motivated by FWCs and Rs 2279 if clients are motivated by MSUs. The actual cost of surgery per client ranges between Rs 1297 (Sheikhupura) and Rs 9080 (Nankana) with the district average of Rs 5189.

\section{SENSITIVITY ANALYSIS}

The revised figures with the new set of assumption (CYP and Birth aversion) for FWCs follow:

Comparison of Table 3 and Table 6 indicate that the cost per birth averted has decreased from Rs 316 to Rs 312; when adjusted for overreporting of pill and condom it decreased from Rs 325 to Rs 321 . Cost per birth averted of condom shows an increase from Rs 1458 to Rs 1637, that of injectables shows a decrease from Rs 3901 to Rs 3794; that of the pill shows an increase from Rs 3296 to Rs 3572 and IUD decreased from Rs 107 to 104. 
Table 6

Cost-effectiveness Measures for Family Welfare Centres (Revised Figures)

(District Level)

FP CONDOM INJ PILL IUD SURG.

Total Cost/Birth

Averted

Total Cost/Birth

Averted (Adj)

Total Cost/Unit

Total Cost/Unit (Adj)

Total Cost/CYP

Total Cost/CYP (Adj) 124
312

$1637 \quad 3794$

2572

104

677

321

2731

3794

5036

104

677

- 2

94

33

109

1808

94

66

109

1808

660

45

181

1299

45

181

\section{SUMMARY OF RESULTS}

The summary of findings of the present study are presented in Table 7 to Table 9.

Table 7

Cost-effectiveness of Family Planning (All Methods)

(District Level)

\begin{tabular}{lccc}
\hline & $\begin{array}{c}\text { FWCs (All } \\
\text { Methods) }\end{array}$ & $\begin{array}{c}\text { MSUs (Few } \\
\text { Methods) }\end{array}$ & $\begin{array}{c}\text { RHS Centres } \\
\text { (Surgery Only) }\end{array}$ \\
\hline Cost/Birth Averted & 316 & 309 & 941 \\
Cost/Birth Averted (Adj) & 325 & - & - \\
Cost/CYP & 124 & 117 & 519 \\
Cost/CYP (Adj) & 129 & - & - \\
\hline
\end{tabular}

Table 8

Cost-effectiveness of Temporary Methods by Type of Service Outlets

(District Level)

\begin{tabular}{|c|c|c|c|c|c|c|}
\hline & \multicolumn{2}{|c|}{ Condom } & \multicolumn{2}{|c|}{ Injectable } & \multicolumn{2}{|c|}{ Pill } \\
\hline & $\overline{\text { FWC }}$ & MȘU & $\overline{\text { FWC }}$ & $\overline{\mathrm{MSU}}$ & $\overline{\text { FWC }}$ & MSU \\
\hline Cost/Birth Averted & 1458 & - & 3901 & 43948 & $\dot{3296}$ & - \\
\hline Cost/Birth Averted (Adj) & 2431 & - & - & - & 5964 & - \\
\hline Cost/CYP & 390 & - & 1046 & 9076 & 863 & - \\
\hline Cost/CYP (Adj) & 650 & - & - & - & 1702 & - \\
\hline Cost/Unit & 2 & 1424 & 94 & 859 & 33 & 1296 \\
\hline Cost/Unit (Adj) & 3 & 2373 & - & $-\quad-$ & 66 & 2376 \\
\hline
\end{tabular}


Table 9

Cost-effectiveness of IUD and Contraceptive Surgery

\begin{tabular}{|c|c|c|c|c|c|}
\hline & \multicolumn{2}{|c|}{$\begin{array}{c}\text { IUD } \\
\text { Motivation }\end{array}$} & \multicolumn{2}{|c|}{$\begin{array}{c}\text { Contraceptive Surgery } \\
\text { Motivation + Motivation } \\
\text { Service Delivery }\end{array}$} & \multirow{2}{*}{$\begin{array}{c}\begin{array}{c}\text { Service } \\
\text { Delivery }\end{array} \\
\text { RHS }\end{array}$} \\
\hline & MSU & FWC & FWC & MSU & \\
\hline Cost/Birth Averted & 147 & 107 & 676 & 338 & 1941 \\
\hline Cost/CYP & 68 & 47 & 181 & 90 & 519 \\
\hline Cost/Unit & 155 & 109 & 1805 & 903 & 5189 \\
\hline
\end{tabular}

It is important for policy-makers to note that the cost per birth averted for family planning or cost per CYP for family planning do not meaningfully compare for the three types of service outlets because each type of service outlet provides a different method mix although they were initially designed to provide all the methods. However, the costs of FWCs and MSUs can still be compared to some extent. Although the per unit cost of each method is substantially higher for MSUs the cost per birth averted and cost per CYP are lower for MSUs as it basically

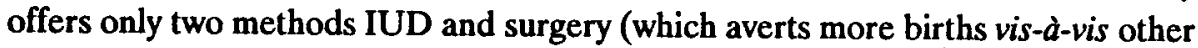
temporary methods) whereas FWCs offer all methods. MSUs only motivate clients for IUD and surgery. The cost per birth averted for RHS reflects cost of surgery only.

The cost per birth averted and cost per CYP for condom and pill are missing from Table 8 because their volumes of output are so low that they cannot be converted into birth aversion and CYP figures. The cost per birth averted for injectable is also very high due to extremely low volume of its output. For practical purposes therefore, the costs of FWCs and MSUs cannot be compared for these three temporary methods. the cost-effectiveness figures for IUD and surgery are presented in Table 9.

\section{POLICY IMPLICATIONS}

The major policy recommendations emanating from the study are:

Due to low volume of activity the fixed costs are dominant (these are capital cost on staffing, rent and other capital items already incurred) yielding high per unit cost. The productivity or volume of activity of the service outlets can definitely be increased by increasing the variable or operational costs and without any change in the fixed staffing and capital costs upto an optimal limit to gain from economies 
of scale. The increase in the volume of activity by every existing service outlet will lower the per unit cost achieving economic efficiency and increase the number of births averted and CPR increasing the demographic impact.

An important policy option is to adopt strategic shifts in terms of various contraceptives mix. There is enough evidence to support the fact that condoms and pills are neither popular nor cost-effective methods nor they are use effective in terms of demographic impact. More emphasis on injectables (popular method), IUDs (cost effective) and surgery (cost and use effective) will definitely be more economical as well as effective in terms of demographic impact. There is however, need to increase acceptance of family planning among younger couples at lower parity for both spacing and reduction in family size.

In order to ensure greater utilisation of existing service outlets and increase the volume of activity to reduce per unit costs, it is crucial to generate more effective demand for family planning.

Demand for family planning can be increase by adopting the following measures:

The use of electronic media to propagate family planning has increase in the past two years. Since television is restricted to urban and semi-urban areas there is need to publicise the FWCs and their location through some other communication media in the communities like announcing in public places, posters in local languages in hospitals, union council and community centre buildings, schools and shops. Similarly, information on methods have to be disseminated.

Side-effects, misconceptions about side-effects and unhygienic delivery of IUDs and surgery leading to infections and complications have been identified as major factors for non-use. The following measures can be adopted to improve the service quality:

- Proper counselling and information on FP methods to potential clients by FWWs and FWAs;

- use of satisfied clients for motivation in group meetings;

- adequate supply of medicines including antibiotics, vitamins and antisceptic solutions for treatment of infections and sterilisation of equipments; and

- effective referral system for complications to hospitals.

It is to be noted that one dissatisfied client does a lot of damage to the programme and so does an ill-informed client. In order to motivate people to have 
smaller families the following measures can be adopted in the long run:

- Aggressive campaign and provision for female literacy nationwide at least upto primary level.

- Use of incentive/disincentive packages for consumers such as concessions on school fees, books etc. to individuals with small families.

- Bonuses and monetary/status rewards/awards to individuals with small families. Similarly disincentives can be introduced for parents having more than say, three or four children.

- In rural areas, various loan packages can tie up family size as a condition.

- Tax benefits to individuals/organisations donating time, capital goods, and building to family planning.

- Pricing of contraceptives on the basis of ability to pay.

\section{REFERENCES}

Ministry of Population Welfare (1992) Foreign Assistance Requirements for PWP during Eighth Five Year Plan, Document Prepared for Donors Meeting, November.

Rukanuddin, A. Razzaque (1990) Country Strategy Paper. UNFPA.

Johnson, Tim (1991) Revised CYP Figures, Programme Performance Indicators Report, USAID, Islamabad.

Janowitz, B., and J. H. Bratt (1992) Costs of Family Planning Services: A Critique of the Literature. Intemational Family Planning Perspectives 18: 137.

UNFPA (1989) International Forum on Population in the Twenty-first Century. Amsterdam Declaration. November.

AID (1989) Moving into the Twenty-first Century: Principles for the Nineties. Family Planning Services Division. April (Draft.)

Bulatao, R. (1985) Expenditures on Population Programmes in developing Countries. Washington, D. C. : (World Bank Staff Working Papers, No. 679.) Gillespie, D. (1989) Financing the Delivery of Contraceptives. In S. Segal (ed) The Demographic and Programmatic Consequences of Contraceptive Innovation. New York. 